\title{
Creating a Sexual Self in Heteronormative Space: Integrations and Imperatives Amongst Spiritual Seekers at the Findhorn Community
}

\author{
by Elizabeth Dinnie and Kath Browne \\ Macaulay Land Use Research Institute \\ Sociological Research Online, 16 (1) 7 \\ <http://www. socresonline.org.uk/16/1/7.html> \\ $10.5153 /$ sro.2287
}

Received: 20 Jul 2010 Accepted: 11 Feb 2011 Published: 28 Feb 2011

\begin{abstract}
Intersections between religion and sexuality are coming onto social science agendas. However, this has predominantly been in terms of its treatment by mainstream religions, particularly Christianity and Islam, and thus in contexts traditionally hostile to lesbian, gay and bi sexualities (LGB). This article extends this by exploring identities and contestations of sexuality within activities that have variously been described as 'New Age' or 'spiritual'. Considering the experiences and interactions of spiritual seekers avoids a nonsocial conceptualisation of 'New Age' which views spirituality primarily as an individualistic experience. The specific focus here is the Findhorn Community, a spiritual community and demonstration eco-village in Scotland. We find that seekers' attempt to resist labelling and categorisation through creating and using individualised sexual (as well as spiritual) expressions. However, tensions stemming from (heteronormative) interactions within the Findhorn community show that sexual diversity and labelling continues to matter. The research demonstrates that sexual fluidity is a privileged position to occupy, but that it is also ultimately unsustainable in that fluid identity becomes re-subsumed in heteronormativity and, eventually, individuals have to come out and identify all over again. The continuing imperative for some LGB people to define themselves as/with 'something', is thus apparent even within supposedly individualized settings and belief systems. Such positioning questions the individuality that is presumed to define New Age spiritualities, and shows how categories of lesbian, gay and bisexual also continue to be deployed at the same time as they are resisted and reinterpreted.
\end{abstract}

\section{Keywords: Individuality; Lesbian, Gay, Bisexual; Sexuality; Spirituality; Findhorn Community}

\section{Introduction}

1.1 In recent years much critical attention has been paid to the increase in religious individualism see Heelas 2008; Heelas and Woodhead 2005; Lynch 2007). However lesbian, gay and bisexual (LGB) ${ }^{[1]}$ people are unusual in that they/we may not choose such individualism so much as have it thrust upon them/us (Wilcox 2003: 16). The rejection, or potential rejection, should sexual identities be visible or apparent by certain religious institutions can mean that for some LGB people forging individual religious and spiritual paths becomes a necessary route to religious/spiritual fulfilment. LGB people who chose (or indeed are forced into) particular spiritual/religious paths can offer important insights into contemporary manifestations of alternative sexualities and 'individualised' spiritual paths. The main contention of this paper is that although many of those engaged in individual spiritual practices may strive for holistic pathways where sexuality and spirituality are interconnected there continues to be an imperative to engage with sexual identities in ways that can be at odds with the ways in which spiritual lives are understood. In an era of sexual 'equalities' and fluidities we are contending that sexual identities continue to matter (see also Heaphy 2008 and Moore 2010), despite popular and academic questionings of collective and fixed identifications, be they around sexuality or spirituality. Not only do individuals align to spiritual collectivities, as we will argue with Findhorn spaces, categories of lesbian, gay and bisexual also continue to be deployed at the same time as they are resisted and reinterpreted. This extends work that asks for the significance of collectivities by noting that such collectivities and interdependencies (Moore, 2010) are in this case mediated through, and indeed as we will show with regard to sexual identifications, at times required for spiritual spaces. 
spirituality. Following an outline of the methods and the place of this paper in the Queer Spiritual Spaces Project, we examine the complexity of lived experiences of lesbians, bisexual women and gay men at Findhorn, a spiritual community in Scotland. Resistance to labels and categories defining or limiting sexuality lead to the expression of novel and unusual sexual identities outside the hegemonic identities lesbian, gay and bisexual. Yet, ironically, such creations and individualised renderings of sexuality also have unintended consequences. Our data leads us to conclude that an individualized and fluid, spiritualized sexuality obscures the ways in which identification as a certain kind of sexual subject continues to be important within knowable communities and modes of belonging. Tensions arise in particular when heteronormative ${ }^{[2]}$ assumptions are revealed in ways that continue to regulate sexuality in these 'open' spaces.

\section{Diverging Roads? Sociology, Religion and Sexuality}

2.1 In general the sociology of religion has paid little attention to the religiosity of Lesbian, Gay, Bisexual and Trans people. Although this situation is changing, with sociologists demonstrating that religion and spirituality are important resources for many LGBT people (Hunt 2009; Yip 2003; Wilcox 2002; 2003), within and beyond sociology much discussion and research continues to be dominated by the 'homosexuality debates' in the Anglican communion (e.g. Vanderbeck et al 2010; Nixon 2008; Keenan 2008; see also Browne et al 2010). The lack of work in the sociology of religion on the experiences of LGBT people, coupled with a focus on the homosexuality debates, can leave the impression that many religions are 'homophobic' (as well as biphobic and transphobic- although these are less well remarked upon); a situation which is in direct contrast to the increasing tolerance and visibility of LGBT people in secular organizations (Yip 2008). Conversely, there has been a rejection by LGBT groups, individuals and people of religion in specific forms (see Browne et al 2010; Yip 2003; Wilcox, 2002; 2003). The perception that LGBT people are not religious, coupled with the influence of Marxism within LGBT studies, means that there are few studies of LGBT religiosity (Wilcox 2003: 17), particularly related to 'New Age' or alternative spirituality [3]. While other social institutions have received attention, for example the family and marriage, spirituality has remained a neglected area; discussions of religious choice and individualism have neglected restriction in this 'supposedly open market' (Wilcox 2002: 498).

2.2 However, any discussion of sexuality and spirituality needs to account for recent moves by queer scholars to unsettle the master categories of gay and lesbian, in part by shifting attention from identities to practices (Corber and Valocchi 2003). Rather than viewing the affirmations of identity as wholly liberating, queer theorists in particular, have theorised these as disciplinary, normalising and regulating structures. Approaching identities as multiple, unstable and regulatory may suggest the undermining of gay politics (and sexual identifications upon which they rest) but for queer theorists it also suggests new and productive possibilities (Seidman 1996, 12). Understanding sexuality as a productive system of regulation, scholars have explored the possibilities of other forms of sexual-social relationships, as well as the entanglement of sexuality with other social differences. Heteronormativity, understood here as the aligning of genders and sexuality (as well as race, class and ability) in ways that both create and privilege certain ideals as 'normal', has been critiqued and challenged by queer scholars, finding heterosexuality (and homosexuality) to be fluid and performed (Butler 1990). Moreover, in an era of 'equalities' and the domestication of (non-threatening) lesbians and gay men, the normalisation of certain gay and lesbian lives has also come under critical scrutiny (Warner 1999;Stychin 2006).

2.3 Following Butler (1990) and others, there has been a move away from naming and categorising towards more fluid engagements with desire, performativities and encounters. This has particular implications for collectives and personal identities built on sexual categories. For example, once a first step towards personal and collective transformation, 'outness' as an empowering form of personal and political identification has been challenged in recent literature. Arguing that the imperative to 'come out' may not have desired political effects, authors point to how it can be used as a trope to marginalise, exclude and express other forms of prejudice (see for example, O'Brien; Vidal-Ortiz; Decena 2008.). Coming out can have an empowering effect on individuals (Valentine \& Skelton 2003), yet the shift towards a regime of compulsory disclosure has been rendered problematic. Coming out is co-present and constitutive of contemporary lesbian and gay performativities such that psychological deficiency, not political or sexual dissent, has been used to explain the behaviour of people who cannot or will not come out (Decena 2008: 406). Patton (1993) argues that coming out reshapes and forms political subjects. Coming out does not reveal a true self that was hidden and psychologically impaired by secrecy, but it links the selves thus constituted to moral mandates; 'identities carry with them a requirement to act, which is felt as "what a person like me does"' (Patton 1993: 147), as well as to other selves forming collectivities and belonging. Legitimacy gained through gay identifications and the requirement for an unfailing repetition of a 'homo-self' at every possible iteration are being contested (Vidal-Ortiz 2008: 488). Yet, as this paper will argue, visible sexual identifications and collectivities continue to be important in questioning pervasive heteronormative assumptions, such that 'coming out' and labelling oneself as gay/lesbian/bisexual remains a political act. Indeed our data links with others (see for example, Kirsch 2000), who question the possibilities of queer thinking for delivering social change and instead notes the place and importance of recognition, community and belonging. This however is not to deny how through processes such as celebrating 'coming out' some forms of 'homosexuality' are legitimised (some would say (homo) normalised) - whereas others remain deviant and beyond the realms of respectability and recognition.

2.4 Sacred spaces, including churches, mosques, temples and synagogues, have often been heterosexualised in part through the exclusion of diverse forms of sexual and gender difference, including lesbian, gay, bi and trans identities and celebrations (Yip 2008: 8). For Christians and others raised in 'traditional' religions (including Islam) same-sex attraction or trans identity can present the difficult choice between religious commitment and gender/ sexual practices and identities (Browne et al 2009; Yip 2003; Wilcox 2003: 10). Coming out can challenge Christian identifications (Wilcox 2002: 500). Although it could be argued that there are polarised responses to this; with some people choosing religion and heteronormative lives, whilst others choosing LGBT lives rejecting religion, the research in this area 
suggests that many compromise and negotiate around both aspects of these identities, practices and beliefs (Gorman 1980; Thumma 1991). Yip (2003) argues that LGBT identities and religious lives are not necessarily oppositional. For many negotiating potential opposition involves reinterpreting belief systems in such a way that alternative sexual identities, practices and lives and religious commitment are not just compatible but are also intertwined. Recent studies have shown a move by those defined as gay and lesbian to negotiate a religious identity based on the individualistic claim that 'this is my religion too!' (Wilcox 2003: 13). Wilcox (2003) points out sexuality and spirituality can be closely linked, such that 'being' gay/lesbian/bi and/or trans is considered a spiritual calling. In Britain Andrew Yip (1996; 1997) has pointed out that a religiously rooted essentialism - the belief that 'God made me this way' - is an important part of the integration of gay men and lesbians in particular.

2.5 Questioning the assumption of mutually exclusive sexual/spiritual identities, lives and practices allows some LGBT people to integrate sexual/gender identity with traditional religious beliefs. For others who do not seek to be part of such institutions, communities and belief systems yet seek to retain an element of the sacred in their lives, one option is to turn to a more individualised spirituality. Spirituality can be appealing to LGBT people because it can reject the spiritual/sexual binary which has been used to create the 'homosexual sinner' in traditional religions (Wilcox 2003; Tacey 2004) as we discuss further below. Such a focus can result in the creation of unique and individual spiritual paths in ways that are different to those who occupy normative sexual and gender subject positions. Yet, such individualisation is also questioned by LGBT collectives as well as the desire for spiritual groupings in places such as Findhorn. In order to engage with spirituality and in this context LGB experiences and identifications (as there were no Trans people in the sample), it is necessary to move beyond the literatures that have worked at their seams to engage with broader contexts of sacred sexualities and queer thinking.

\section{Sacred Sexualities: The Project of the Self}

2.6 Whilst multiple, divergent and contested, so-called 'New Age' spirituality offers insights into the construction of a spiritual self and is important in understanding contemporary manifestations of belief beyond traditional religions. The term spirituality typically includes a number of overlapping, and sometimes contradictory, teachings that cover a wide range of activities many of which aim at the rediscovery of a lost sacredness in everyday events and objects, including the human self (Hunt 2003: 131). With roots in nineteenth century esotericism, new religious movements of the 1970s, well-being culture of the 1980s and indigenous and folk religions of pre-modernity, spirituality includes a diverse range of practices, beliefs and ways of life (Bruce 1996; Heelas 1996; Hunt 2003). Activities range from yoga to tantra, sculpting to gardening, Zen meditation to astroshamanism. Although diverse and multifaceted, often central to practices included under the 'New Age' emblem is the aspiration to re-discover a true self; a divine core which is the true essence of the human spirit (Heelas 1996; Sutcliffe 1995).

2.7 However, scholarly interpretations which view spirituality as fundamentally concerned with the inner life offer only a vague and loose definition for what is a bewildering variety of practices and groups. Recent studies of New Age spirituality have challenged sociological orthodoxy which presents it as a realm in which the individual's autonomous ability to act is paramount (see for example Wood \& Bunn 2009; Aupers and Houtman 2006; Heelas 2006). Although recognising that connecting with an inner self is the main purpose of many, if not all, New Age activity, there is increasing recognition that there is more relationality, socialization and strategy in the New Age milieu than previous scholars have allowed for. So although many spiritual activities are concerned with the self there are powerful social forces, such as power dynamics and personal biography, acting upon and within the spiritual milieu which make spirituality much more than a self-religion. The 'self' can thus be seen as an assemblage of inter-relationalities, stemming from practices that recreate forms of spiritualities (and sexualities), even those that emphasise the individual.

2.8 In contrast to some mainstream religious views of the self as inherently sinful or flawed New Age spirituality sees the self as a manifestation of divine intelligence and energy (Lynch 2007: 55; Heelas 2006). Rather than something to be controlled and disciplined, the self is inherently good; embodied experiences are seen as valid sources of revelation about the divine, and the ongoing development of the self is seen as part of the wider divinely inspired unfolding of the cosmos (Lynch 2007; Sutcliffe and Bowman 2000). This emphasis on the essential 'goodness' of the self resonates with the importance and autonomy accorded to the individual self in society more generally; a phenomena that Charles Taylor has called 'the massive subjective turn of modern culture' (Heelas and Woodhead 2005). Those who follow New Age spirituality thus seek to discover a 'true' self through liberation from oppressive and corrupting socialized identities (Heelas 1996; Bruce 1996) rather than seeking to find fulfilment through the enactment of idealized social roles (Heelas \& Woodhead 2005). The idea of a 'real' divine self underlying social identity can be read as a form of essentialism, a belief that at our core there is some immutable, fixed essence untouched by culture or environment. As we shall discuss, this can create tension between spirituality and some expressions of sexuality.

2.9 The holistic idea that the divine can be found everywhere, rather than the world being divided into sacred and profane, means that 'deviant' sexualities can be integrated into the whole of life and not left on the margins as an embarrassing extra that we strive to repress or ignore (Tacey 2004: 114; Lynch 2007). Spiritual beliefs which bring sexuality into the sacred sphere can mean that LGBT people do not have to make a choice between their beliefs and their sexuality/gender identity, as the latter can be integrated into their spiritual journey. However, as we will show, how these beliefs are manifest through the integration of sexuality, LGB identifications and the inter-relations at the site of the Findhorn community are not necessarily straightforward or indeed 'open'. Rather than 'intersecting' spiritualities and sexualities exploring tensions and overlaps (see Browne \& Dinnie, 2010), we instead read sexual identifications through the way they are manifest in and in turn create spiritual spaces, and how spiritual spaces (re)form sexual identifications. 
3.1 This research was undertaken as one case study for the Queer Spiritual Spaces project, funded under the AHRC/ESRC Religion and Society programme. The project looks at the place of the sacred in the lives of LGBT people who are also members of non-dominant faith groups, including Quakers, Muslims, Buddhists, and the Non-aligned Spiritually Curious. It was undertaken by a research team, who employed post-doctoral research fellows to undertake four case studies (see Browne et al. 2010). Each case study explored a range of issues that pertained to the relationships between sexual/gender identities and spiritual practices. The research was qualitative consisting of focus groups and interviews and was undertaken between April 2008-August 2008 (for further details see http://www.queerspiritualspaces.com). The data for this paper came from the Findhorn case study and specifically arose from the complex intersections between spirituality and sexuality that were apparent in this case study. The data for this paper was analysed by the authors and the paper was reviewed by the other researchers in this project. Analysis followed an inductive process; initial conceptual ideas suggested by the data led to further interrogation and refinement of concepts as writing up progressed. Data for this paper was drawn from the initial themes and then the data further interrogated to explore the emerging concepts. For further details of the study and the overlaps and intersections between the case studies please see Browne et al. (2009).

3.2 For this case study eleven in-depth interviews and two focus groups (each consisting of 5 participants) ${ }^{[4]}$ were conducted by one of us with visitors and residents ${ }^{[5]}$ of the Findhorn community, a spiritual education centre and demonstration ecovillage in Scotland (see also Browne \& Dinnie 2010). The research was designed in accordance with ethical guidance set out by ESRC and AHRC. Participant information sheets were given to all participants and informed consent was obtained prior to the research taking place. Pseudonyms have been used however the naming of Findhorn as the research site could mean that some participants are potentially identifiable. Nonetheless, given the size of Findhorn, the turnover of people and movement between positions within the community it would be difficult to identify any specific individual in this study. In naming Findhorn and the position of participants within the community we are following others who have researched and written about this site in this way (Sutcliffe 2003; Sargisson 2000).

3.3 Founded in 1962 the Findhorn community has become one of the most well-known spiritual centres of modern times (Heelas 1996, Sutcliffe 2003). Originally a small group of people living together and quietly communing with nature Findhorn has become an international centre of spiritual education and ecological demonstration with around 500 residents which annually attracts over 2,000 visitors to its residential workshops and conferences (see http://www.findhorn.org). Located at two campuses in Moray, the community consists of the Foundation (an education centre and the largest organization) and around 30 small and single-operated businesses and services in such areas as holistic education, organic farming, energy production, retailing, building, alternative therapies and healing, bed and breakfast and holiday accommodation, creative and performing arts and sustainable development (Dinnie 2008).

3.4 The Foundation has a year-round programme of residential workshops, conferences and special events which since the early 1980 s has included workshops for gay, lesbian and bisexual people. The absence of trans should be noted here. Although there are some trans individuals at Findhorn this research did not capture their experiences. Thus, rather than tokenistically use the category LGBT, we more accurately represent the sample using LGB.

3.5 Such events include gay and lesbian experience week, an alternative to the standard experience week (an introduction to community life); women2women, a personal and spiritual inner journey for lesbians (Findhorn 2008); and gay men's retreats at the community's house on lona on the west coast of Scotland.

3.6 The idea of workshops for gay and lesbian people was at first opposed by some community members. Criticisms voiced by others were recounted by George and included the idea that workshops 'should be for everyone' and if 'we started having workshops for gay people we would end up having them for stamp collectors' (George, a participant in this research and long-term staff member of the Foundation). Early notices for meetings to discuss the workshops were removed from community notice boards. Their disappearance was interpreted by some residents as an esoteric 'sign' that there was no place for such workshops at Findhorn, a convenient way to sideline homophobia or power struggles between different groups within the community. In the summer of 2008 during the fieldwork for this project there was also some controversy when the lesbian and gay experience week was removed from the programme (see Browne \& Dinnie, 2010[6] . A community meeting was held to discuss not only the workshop but the issue of sexuality within the community more widely.

3.7 The issue of sexuality touches on wider issues of authority, discipline and structure. Part of the problem is that because the over-arching belief system emphasises that divinity is found within each person then everyone can claim to have direct access to the truth (Bruce 2002). The problems that epistemological individualism raises for authority and decision making have been managed in various ways over the course of the community's history and are only briefly mentioned here (see also Rigby 1972; Sutcliffe 1995; Dinnie 2008). For the first few years of the community's existence members were firmly under the leadership of the founders, Peter and Eileen Caddy, a situation that could be seen to contradict the belief system (Rigby 1972). As the community grew its main purpose changed from creating a way of life to education and demonstration (Dinnie 2008). Having an educational purpose enables organizations to adopt a service relationship with wider society, rather than one based on opposition (Kanter 1972). Decision-making processes and community structures became more bureaucratic and the original charismatic founders left. In recent years the boundaries around the Foundation (and hence the community) have become more porous as profit-orientated businesses have moved into the wider community and new businesses have sprung up that were never part of the Foundation. The general trend then has been one of privatization and decentralisation, so that rather than a single community Findhorn can be seen as an association of many different groups and organizations congregated around a central 
organization (Riddell 1991; Metcalf 2004). Findhorn offers an important site to explore the interactions between sexuality and spirituality, particularly as this diversity attracts visitors as well as residents. The next section will explore how LGB people discuss integrating their sexuality with a spiritual journey.

\section{'It's much more than sexual': The problems with labels}

4.1 Moving beyond labels and the need for identities participants in this study expressed aspirations to integrate sexuality as part of their spiritual journey. In this context, a foregrounded LGB sexuality can be perceived as problematic because it is constraining, as Lucinda, a wider community resident, describes;

In terms of my sexual identity it's just Lucinda, so it is, and my ideal world is that I don't see the sex of the, the physical sex of the person.

Interviewer: So would you use any labels, like lesbian, gay, queer?

They trigger me. I loathe them. I struggle with them. I think it's because I've a fear of getting tied into the box. I think that it's just labelling in general, because of my very rigid upbringing. Very structured. Very labelled, and it was if you were this you were always this, and there was no space for changing it, and that is probably actually the basis of it, because when I came here to Findhorn it was to get out of boxes. My sexuality is one thing that I still struggle with, because I have balance in the rest of my life, but where my sexuality, its where my rigid upbringing comes in. I'm either straight or I'm gay, I can't be in-between, where, where I'm open to both. It's either one or the other, which is my rigid upbringing, so that's why I just use the label Lucinda because then it is whoever I am at the moment.

4.2 This 'balance' that Lucinda strives for is one where she is no longer restricted by labels but can be 'whoever I am at the moment'. She explores the ambiguities of sexual identifications and yet notes she still 'struggles with this'. The 'getting out' of boxes that Lucinda seeks through spirituality is challenged by her sexuality, and there is clear tension in her account that places 'balance in the rest of my life' in conflict with a sexuality that can't be 'in-between'. She attributes this to her 'rigid upbringing', but it is also clear that the 'rest of her life' at Findhorn plays a part in constituting this tension. Thus there continues to be tensions between a sexual identification and a holistic spirituality, even where participants tried to 'make it not an issue'.

4.3 Where spiritual beliefs and feelings are recast as 'natural', similar to Christian assertions of being 'made by God' (Wilcox 2003; Yip 1996; 1997), the marking of deviance by others in heteronormative dualistic ways (gay/straight, man/woman) can be contested. As Fiona says:

I'm so firm within myself that what I live and what I feel is natural. I'm most excited about stuff that I'm learning through my partner actually. About gender, and non-duality in terms of gender because that was never really in my awareness, until I met her. And its bringing the whole non-duality concept, which I was familiar with in the past, to gender and sexuality, and then again it was another click, of course why has everything been segregated into man and woman, and gay and straight and, we've just got two ends of a stick, and everyone has to be either this, or that. If there's a lot of spirituality around, talking about bringing non-duality in, why is nobody talking about how that's relevant in terms of sexuality? Cos it's a very taboo thing to do, and it feels, it's very confirming to me. And, l'd just like to imagine what the world would be like if people didn't walk around fulfilling a man's stereotype and a woman's stereotype and, mixing things up and just being completely who they are. And if they're attracted to someone who kind of has the same parts as they do then, who cares? It's just all an expression of the same thing.

4.4 Echoing arguments that question the binaries of man/woman, gay/straight (Browne 2004; Butler 1990; Halberstam 1998); resolving these binaries becomes a spiritual lesson by 'imagining' the world in nondualist terms. Fiona, who is resident in the wider community, flattens sexual and gender difference declaring her ideal as 'all an expression of the same thing'. Yet she also alludes to the 'taboo' nature of such discussions of sexuality and gender that are not part of the broader spiritual lessons in this area.

4.5 The rejection of labels and the search for individual pathways meant that questions regarding identities elicited insightful and detailed descriptions relating to sexuality. Allison's response shows how she incorporates and rejects different representations of 'her' sexuality:

How would I present myself to the world? I wouldn't say lesbian, that's not right, I don't identify with the culture of lesbian. I wouldn't say bisexual, cos that doesn't incorporate all genders. So I think it's-, I don't know. I can't actually say it to people but like omnisexual, or pansexual, just a space where it's really connecting to another human being. So the way I really describe it at this point is 'hey, like l've just been in relationship with a woman for 3 years', that's my explanation.

4.6 Allison, a resident in wider community, 'queers' sexual identity by rejecting normative labels, categories and boundaries, including those that delimit sexual identity and gendered attractions. She focuses on spaces of connection and her relationship allowing others to read her sexual identity from this without locating herself alongside the 'culture of lesbian'. Her connection to 'another human being' is not only sexual- it has spiritual connotations and implications. Whilst she sees her sexual/spiritual life as inseparable, she allows that others can use these categories to define her behaviour:

Actually, people are really good about it. They don't go 'so you're lesbian', or 'so you're this', or 'here's the box now sit in it'. They actually say, 'oh yeah, that's interesting', 'wow, a 
relationship with a woman'. They use that wording, and it makes me feel exempt from having to tick all the boxes. I can just say, 'this is actually where I fit in, kind of'. Some people say 'gay' and I'm like, 'uh, if you really must, fine, but I still look at guys'.

4.7 Allison's description not only questions boundaries and categories, it also puts sexuality in flux. Those who read her relationship and comment on the relationship rather than her sexuality are welcome, however the imperative to define her ('if you really must') is tiresome and inaccurate for her.

4.8 Rendering sexual identifications as associated with relationships and exploration can refuse the presumed fixity of (sexual and spiritual) categories (Butler 1990; 1993; Corber and Valocchi 2003). Sasha, a staff member, does not like sexual categories because they fix what for her is constantly changing. She does not want to be limited by something to which she feels she has to conform:

\begin{abstract}
I think the term that I'm most comfortable with and that I use to people that know me, would be just fluid really. I don't tend to name my sexual orientation or pin it down. But to people who I don't know or who I only have a quick moment to, you know, I could use lesbian. I don't feel entirely comfortable with that because it's very limiting in a way.
\end{abstract}

Interviewer: Why is it limiting?

Because it implies that it is something that I am and that I will be forever. It's like a static thing. Its not, there's no room for change or for life to happen. I've used bisexual as well but I didn't feel entirely comfortable with that either because the whole thing for me is complicated by my gender identity. So I don't feel like any of those terms, lesbian or bisexual, really covers, you know, what I feel my sexual orientation is. I could use pansexual maybe but mostly, yeah, just fluid.

4.9 In seeing her sexuality as 'just fluid', Sasha resists imperatives associated with lesbian and bisexual which 'pin it down' and mean that 'there's no room for change or for life to happen'. Yet she also recognises the importance of deploying identifications such as lesbian expediently to 'people who I don't know'. Drawing on the recognitions that are associated with this category, Sasha appeals to a collective understanding that can place her in 'a quick moment'. Interestingly the negotiation of sexual categories is tied into spirituality where both are constantly evolving rather than being fixed, located and stable:

I think that in the early stages of me thinking about it [spirituality] and feeling into it, I kind of sensed that it was, because, it was transformative, in a way, for me. And the way that I saw myself, saw the world, and the way I started thinking about it was also transferable to other things and it was like awakening somehow to something. Yeah, a reality that I hadn't seen before maybe, you know, but also the kind of realization that for me it's a process not like that's the ultimate truth, its evolving somehow. That how I see, yeah, gender, sexuality, everything really, in a process, evolving.

4.10 Sasha's spirituality includes her belief that everything is 'evolving' and she applies this to 'gender, sexuality'. This leads her to focus on the 'process' rather than 'the ultimate truth', echoing attempts to shift the focus of sexuality from identities to practices, and making a distinction between the normative structures privileging heterosexuality and individual patterns organizing sexual lives (Butler 1990; Corber and Valocchi 2003). The conscious consideration of such sexual-spiritual fluidities is formed through understanding the need to work towards a higher consciousness through practices of the self. Nevertheless participants also continually re-connect, and identify, with sexual (and spiritual) collectivities.

\title{
Making it 'big': Heteronormativity and identification
}

5.1 Many participants in this case study described 'their' sexuality in highly individualised ways. This resulted from, and also led to, a questioning of labels and fixed categories around identity, including sexual identity. So, it should not be surprising to find that participants felt uncomfortable entering situations and interactions in spaces that were clearly demarcated by sexuality, as Lucinda says:

I actually find it hard to go into gay meetings and stuff like that. It was like, we had a gay brunch with the women who love women workshop, and I was asked to brunch for it, and its basically a lesbian workshop, and I struggled with that, because of the label with it. Yeah, my sexuality is one part of me and I really don't like going into spaces where it takes me out of the other parts of me, that's maybe a good way of describing it. I don't know if I would ever stand up and say that I'm gay or that I'm a lesbian. I probably would, because again its exclusion, and I'm trying to include instead of exclude, yeah, I tend not to make it an issue.

5.2 Lucinda's invitation to a 'gay brunch' shows that she is read and understood in a particular way despite her discomfort in being visible by going to a gay meeting. There is a visibility in attending a brunch in a community space which assumes a homogenous 'us' that is somehow different and thus separate from an excluded 'them', which 'takes me out of the other parts of me'. Lucinda's refusal to 'make it an issue' can be read as resistance to normative structures which prevent some sexual identities from going unmarked or seeming 'right' in the way heterosexuality can. However, not making 'it' an issue is also a refusal to engage in power struggles over who gets to define who, as we will discuss below.

5.3 Intertwining sexualities and ('New Age') spiritualities can create space for alternative gender and sexual expressions but it can also unintentionally allow for heterosexual assumptions when these expressions are not specifically questioned or 'queered'. Diana recalled an experience in which her 'failure' to 'disclose' may have led to an assumption about her sexuality, which was then called into question by her presence on a workshop for lesbian and bisexual women: 
I was doing woman to woman workshop, l'd met somebody at a party just beforehand, a man, and we'd had a really long conversation and he'd obviously assumed I was heterosexual because l'd mentioned my kids, and l'd never... it's kind of like that thing, when do you mention [it]? There was no reason in that conversation for me to mention my sexuality. And he was working at Cluny. I saw him. I said hello and he looked at me and walked by so the next time I saw him I said to him 'do you remember me? We had this long conversation at this party', and he says 'yes', and I said well 'why', you know, 'I just said hello you're not saying hello back?' And he just walked by again. And the only assumption that I could make was that I was on this woman to woman and he now knew I was a lesbian and had made a sort of like, you know, that wasn't who I thought I was talking to [later in the interview]

Its like, people make assumptions. So you either go along with that assumption or you say something. And by saying something you've made it big and it shouldn't be big. It should be part of everyone's kind of, everyone's on a continuum, as far as I'm concerned. Some people see themselves as entirely heterosexual. Some people see themselves as entirely lesbian and blah, and all of that you know is absolutely fine. But it's all, it's all just part of the ebb and flow and it's just great, but it's like it becomes something big because of having to explain or because of other peoples'-. If everybody kind of saw it as part of the ebb and the flow and it didn't really matter and they didn't make any assumptions then it wouldn't kind of be big.

5.4 Diana is resident in wider community; she uses the term 'big' four times and this offers important insights into how the 'ebb and flow' and 'continuum' is disrupted by labelling that is at times both detested and necessary. Firstly she makes 'it' (her sexuality) 'big' by 'saying something'; however her second use of the term 'big' clarifies why this is an issue, particularly because the labelling of sexuality disrupts the (heterosexual) assumptions of others. As with Fiona above, the hidden power relations that recreate heterosexuality as normal are contested here. At one point Diana appears to see 'making it big' as in some way her fault. However, she then notes that these sexual assumptions should not have been there in the first place. Thus, 'revealing' alternative sexualities can create the 'non-normative' as something that questions, perhaps queers, spiritual continuity and ebbs and flows. Moreover, Diana's linking of the spiritual and the sexual is not always apparent, leading to tension in encounters where sexuality continues to matter to those who seek to define the interaction normatively.

5.5 Sexuality also came to matter to participants when moves between individual and shared (spiritual) experiences were undertaken. Sasha explains that although categories limited 'my freedom to be myself' sharing 'community' spaces was inspiring.

So it was inspiring for me to be there [in a gay and lesbian workshop]. It was also inspiring to share, for myself, and to talk about our community and to see how that landed with the people in the room. So inspiring I think but also something uncomfortable around being there purely because of, I think it's the 'who identifies who?' or 'do I get to identify myself?' or 'do they identify me as?'. So I wouldn't have been asked unless I'd been identified as something so, already it's a little for me like, does this limit my freedom to be myself or can I go in and be completely open? So dealing with that edge a bit and maybe it's just an internal one, and maybe it's actually, you know, that maybe there would have been some reactions if I went into certain topics.

5.6 Sasha's narrative points to the tensions of 'who identifies who' and how one gets into a room to 'talk about community' without such naming. The perception that she has already been 'identified as something' creates an 'edge' between spiritual/sexual, individual/collective identification. Whilst neither spiritual/sexual is defined or definable, there is still a recognition that there may be some 'reactions' that differentiate between those who are supposedly 'the same'.

5.7 The questioning and rejection of labels was not ubiquitous across the sample, indeed labels could be used when they were an expression of the inner, spiritual self. Males interviewed for this research were generally happy to identify as gay men. At the end of the gay and lesbian experience week there was a 'gay-lidh' rather than a ceilidh. This was not without tension; some visitors said they would rather have a simple quiet evening but the organisers felt it was important to mark this experience week as different to a 'normal' (i.e. not gay) workshop. Experience weeks for different nationalities (Italian, German, Japanese) and ages (family, gentle) do not mark the end of their workshops in this way. George, a staff member, felt it was important to be visible and noted the reluctance to being called lesbian more than gay:

I feel that is very very important [to be visible] and I have been a bit puzzled about this. Ok so the new generation seem to not identify with whatever and certainly don't like being called lesbian. It's mainly lesbian more than gay really, which is a complete surprise to me. But then I think well maybe it's partly because they haven't really had the struggle that it has been difficult

5.8 Here sexuality matters through the call for labelling and a struggle for visibility in gender differentiated ways. What perplexes George is exactly what has been explored in the previous sections, namely by not aligning themselves with public displays and utterances of acceptable LGB categories LGB spiritual seekers can create personalised non-heterosexual sexualities, but even in these personalisations there are moments, however reluctant and contingent, of association with particular labels. Arguably this reflects a paradoxical position that is at once homo and hetero -normative. It reflects both privilege in being in a community where lesbian, gay and bisexual lives are supposedly acceptable and being 'out' to others is not always necessary, and a recognition that unless alternative sexual identities are known, performed or disclosed then heterosexuality is assumed. The irony of putting the self first is that it reveals how heteronormativity continues to operate as an unmarked status of self-identity. George, however, does not 
relate naming to segregation of the self and a lack of attention to the 'whole'. Such complexities point to diverse negotiations of spiritual/sexual selves that defy easy or linear accounts and cannot be bounded within the spiritual OR the sexual.

\section{Conclusion}

Holly: It's much more than only sexually, first that is already actually a very narrow question. This is comment on the whole research cos if I only have to answer on that it means that I'm only talking about my sexual or gender identity and for me being a lesbian has influenced every aspect of my life, so it is much wider than only sexual oriented.

The last years it's definitely [been] very clear that I needed even to identify myself again as a lesbian, to make it visible because it's very easy in this still heterosexual world to become invisible, especially if you don't have a relationship and people don't see with who you are, it is automatically believed that you are heterosexual, and I thought for that reason I have to, even in a community on a spiritual base I have to come out as a lesbian again

6.1 The historic academic separation of, and presumed antipathy between, religion and particular sexual lives is further explored through a contemporary site of New Age spirituality. Although spiritual seekers would like spiritual notions of holism to intertwine sexuality and spirituality in presumably liberal and individualised ways, our data paint a more complex picture. By focusing on interactions and practices we also avoid the relatively non-social conceptualisation of New Age that relates this solely to religious practices and beliefs. By focusing on social interactions, identities and experiences, we found, perhaps unsurprisingly, the participants in this study did not identify with the labels which we, as researchers, were trying to explore. Neither did they like going into places and situations that were specifically marked and defined by sexuality. Instead, participants drew on individualised and innovative resources to define their sexual identity and to resist labelling and social roles that more traditional sexual identities carry with them.

6.2 Holly's realization that 'I have to come out as a lesbian again' reinstates the intention to be visible as a sexual subject, demonstrating the fluidities and tensions that are the crux of this paper. The imperative to be visible as LGB has not yet fully abated, even in supposedly liberal situations where 'anything goes' questioning some assertions of queer post-identity politics. Spiritual spaces may not be as open and harmonious as either expected or desired and sexual difference is still marked and noted even where it is then 'ignored'. Consequently, and perhaps contradictorily, the spiritual aspiration to act 'from within' can mean distancing oneself from social roles and public cultures of sexuality, whilst also recognising that these are at times necessary in creating and negotiating a sense of self and resisting heteronormative assumptions. The experiences of LGB people at Findhorn which we represent here show that selfreflexivity has to be negotiated within certain heteronormative frameworks which define non-normative sexual lives, identities and experiences. There are clear tensions here in the ways collective and individual practices, and collective identifications are negotiated: a wholly privatised non-normative sexuality can lead to assumptions of heterosexuality where identification is not made explicitly clear, yet constraints 'limit my freedom to be myself' when and where one is identified as 'something'.

6.3 Holly, similar to other participants, in aligning herself with a particular sexual identity and culture, also undermines the imperative to individualism which often neglects the situational contexts which inform life biographies (Walliss 2002). Indeed the very fact that people go to Findhorn demonstrates that they are looking for relational experiences of spirituality, not just individual ones. Problematizing non-hegemonic sexual expression reminds us that sexual desire and behaviour are always situated within social conditions that shape its expression (O'Brien 2008). The spaces and interactions highlighted here point to contexts where the pervasive effects of heteronormativity are reinscribed, even as they are challenged by ideas about identity and social roles. Therefore, although participants can be read as seeking to live the fluid identities that queer theory proposes (and that were connected to certain spiritual belief systems), the research demonstrates that not only is this a privileged position to occupy but is also ultimately unsustainable in that a fluid identity becomes re-subsumed in heteronormativity. Eventually, as Holly's experience demonstrates, individuals often have to 'come out' and identify over and over again. This critique ties in with the desire for community identity (both spiritual and non-heterosexual) in order to facilitate change and growth (see also Kirsch, 2000). We thus finish by contending that whilst research needs to continue to explore that which questions LGB (and urgently T) identifications and collectivities, and spiritual integration and autonomy, we must also be aware of the endurance of heteronormativity, particularly where 'acceptance' is presumed. The requirement for sexual identifications (as well as community and belonging) outside of presumed heterosexuality has yet to dissipate.

\section{Notes}

${ }^{1}$ The more common acronym LGBT includes lesbian, gay, bisexual and trans people however this study only includes LGB people. Therefore, this paper only discusses sexuality rather than sexual/gender identities. Rather than seeing these as distinct or necessarily having separate spiritual experiences, this gap will be discussed later as partly constructed through research recruitment (such that trans people refused to be involved in the research and therefore should not be tokenistically represented here) and as a function of forms of power that operates between LGBT people. This points to a significant area of research that needs further augmentation.

2 By heteronormativity we mean a set of gendered and sexualised norms that create particular versions of normative heterosexuality and gender identifications. This set of norms works to invisiblise the continual imperative to reproduce specific forms of heterosexuality and normative male/female identities. As a result the dominance of heterosexuality often operates in unnamed ways that make it difficult to expose or dislodge (see Butler 1993: Browne 2004). 
${ }^{3}$ One exception to this is the literature, although not large, on the Wicca community.

${ }^{4}$ Coincidentally one group was all female and the other all male.

5 Participants were aged between 20 and 60, 9 were female and six male; from seven different countries; were white and 'middle class'. Three were staff members of the Findhorn Foundation, 7 were community members and 5 were visitors at the time of the research. further details of the data collection and how sample characteristics were obtained are available in Browne et al. 2009.

${ }^{6}$ For further data on the tensions between sexuality and religious individualism within the setting of the Findhorn spiritual community, see Browne and Dinnie 2010.

\section{References}

AUPERS, S and Houtman, D (2006) 'Beyond the Spiritual Supermarket', Journal of Contemporary Religion, vol. 21, no. 2, pp.201-222.

BROWN, G (2008) 'Thinking beyond homonormativity: performative explorations of diverse gay economies', Environment and Planning A, vol. 41, no. 6, pp.1496-1510 [doi:10.1068/a4162]

BROWNE, K (2004) Genderism and the bathroom problem: (Re)materialising sexed sites, (re)creating sexed bodies. Gender Place and Culture, vol. 11, no. 4 pp. 331-346.

BROWNE, K Munt S \& Yip, A (2010) Queer Spiritual Spaces. Aldershot: Ashgate

BROWNE, K \& Dinnie, E (2010) New Age Spiritualities: Findhorn and the Sexual Self in Browne, K, Munt, S \& Yip, A (eds) Queer Spiritual Spaces. Aldershot: Ashgate

BRUCE, S (1996) Religion in Modern Britain. Oxford: Oxford University Press.

BRUCE, S (2002) God is Dead. Oxford: Blackwell.

BUTLER, J (1990) Gender Trouble. New York: Routledge.

BUTLER, J (1993) Bodies that Matter. London: Routledge.

CORBER, R J \& Valocchi, S M (2003) Queer Studies. Malden, MA: Blackwell.

DECENA, C U (2008) 'Profiles, Compulsory Disclosure and Ethical Sexual Citizenship in the Contemporary USA', Sexualities, vol. 11, no. 4, pp.397-413. [doi:10.1177/1363460708091741]

DINNIE, E (2008) Managing Individuality: An Ethnography of the Findhorn Foundation Community. PhD Thesis: University of Aberdeen.

FINDHORN FOUNDATION (2008) Workshops and Events November 2008-April 2009: $<$ http://www.findhorn.org>

GORMAN, E M (1980) A New Light on Zion. Ph.D. Thesis: University of Chicago.

HEAPHY, B (2008) 'The Sociology of Lesbian and Gay Reflexivity' in: Sociological Research Online 13: <http://www.socresonline.org.uk/13/1/9/heaphy.html>

HEELAS, P (1996) The New Age Movement. Oxford: Blackwell.

HEELAS, P and Woodhead, L (2005) The Spiritual Revolution. Oxford: Blackwell.

HEELAS, P (2006) 'The Infirmity Debate: On the Viability of New Age Spiritualities of Life', Journal of Contemporary Religion, vol. 21, no. 2, pp.223-240. [doi:10.1080/13537900600656066]

HEELAS, P (2008) Spiritualities of Life. Oxford: Blackwell.

HUNT, S J (2003) Alternative Religions. Aldershot: Ashgate.

HUNT, S J (2009) Contemporary Christianity and LGBT Sexualities. Aldershot: Ashgate.

LYNCH, G (2007) The New Spirituality. London: I.B. Tauris.

NIXON, D (2008) ' "No More Tea, Vicar". An Exploration of the Discourses which Inform the Current Debates about Sexualities within the Church of England', Sexualities, vol. 11, no. 5, pp.595-620. [doi:10.1177/1363460708089426]

KANTER, R M (1972) Commitment and Community; Communes and Utopias in Sociological Perspective. Cambridge, MA: Harvard University Press. 
KIRSCH, M (2000) Queer Theory and Social Change. London: Routledge

METCALF, W (2004) Community Living. Forres: Findhorn Press.

MOORE, A (2010) 'I' and 'We' Identities - an Eliasian Perspective on Lesbian and Gay Identities'. In Sociological Research Online 15: <http://www.socresonline.org.uk/15/4/10moore.html>

O’BRIEN, J (2008) 'Complicating Homophobia', Sexualities, vol. 11, no. 4, pp.496-512. [doi:10.1177/1363460708093457]

PATTON, C (1993) 'Tremble, Hetero Swine!' in M Warner (Ed.) Fear of a Queer Planet, pp. 143-77. Minneapolis and London: University of Minnesota Press.

RIGBY, A and Turner, B S (1972) Findhorn Community, Centre of Light: A Sociological Study of New Forms of Religion. In: M Hill (Ed.) Sociological Yearbook of Religion in Britain. London: SCM Press Ltd., pp. 72-86.

RIDDELL, C (1991) The Findhorn Community, Creating a Human Identity for the 21st Century. Forres: Findhorn Press.

SARGISSON, L M (2000) Utopian Bodies and the Politics of Transgression. Routledge, London

SEIDMAN, S (1996) Queer Theory/ Sociology. Cambridge, MA: Blackwell.

STYCHIN, C (2006) Las Vegas is not where we are: Queer readings of the Civil Partnership Act. Political Geography, vol. 25, pp. 899-920. [doi:10.1016/j.polgeo.2006.05.003]

SUTCLIFFE, S J (1995) The Authority of the Self in New Age Religiosity: the Example of the Findhorn Community. Diskus, vol. 3, no. 2, pp. 23-42.

SUTCLIFFE, S J (2003) Children of the New Age. London: Routledge.

SUTCLIFFE, S J and Bowman, M (2000) Beyond New Age. Edinburgh: Edinburgh University Press.

TACEY, D (2004) The Spirituality Revolution. East Sussex: Brunner-Routledge.

THUMMA, S (1991) 'Negotiating a Religious Identity'. Sociological Analysis, vol. 52, no. 4, pp.333-347. [doi:10.2307/3710850]

VALENTINE, G and Skelton, T (2003) Finding oneself, losing oneself: the lesbian and gay 'scene' as a paradoxical space. International Journal of Urban and Regional Research, vol. 27, no. 4, pp.849-866. [doi:10.1111/j.0309-1317.2003.00487.x]

VANDERBECK, R M, Valentine, G, Ward, K, Sadgrove, J and Amdersson, J (2010) 'The Meanings of Communion: Anglican Identities, the Sexuality Debates, and Christian Relationality' In Sociological Research Online 15: <http://www.socresonline.org.uk/15/2/3/vanderbeck.html>

VIDAL-ORTIZ, S (2008) “ "The Puerto Rican Way is more Tolerant”: Construction and Uses of 'Homphobia' among Santería Practitioners Across Ethno-Racial and National Identification', Sexualities, vol. 11, no. 4, pp.476-495. [doi:10.1177/1363460708091745]

WARNER, M (1999) The Trouble with Normal: Sex, Politics, and the Ethics of Queer life. New York: The Free Press.

WALLISS, J (2002) The Brahma Kumaris as a Reflexive Tradition. Oxon: Ashgate.

WILCOX, M M (2003) Coming Out in Christianity. Bloomington, IN: Indiana University Press.

WILCOX, M M (2002) When Sheila's a Lesbian: Religious Individualism among Lesbian, Gay, Bisexual, and Transgender Christians. Sociology of Religion, vol. 63, no. 4, pp.497-513. [doi:10.2307/3712304]

WOOD, M and Bunn, C (2009) Strategy in a Religious Network, Sociology, vol. 43, no. 2, pp.286-303. $<$ http://www.queerspiritualspaces.com> [accessed 21/07/09]

$<$ http://www.findhorn.org > [accessed 21/07/09]

YIP, A K T (1997) Gay Male Christian Couples: Life Stories. Westport, CT: Praeger.

YIP, A K T, Heaphy, B and Thompson, D (2003) Lesbian, Gay and Bisexual Lives over 50. Nottingham: York House Publications.

YIP, A K T (2008) Researching Lesbian, Gay and Bisexual Christians and Muslims: Some Thematic Reflections In Sociological Research Online 13: <http://www.socresonline.org.uk/13/1/yip.html> 